\title{
Green infrastructure and low energy architecture for eco-tourism in Asinara island
}

\author{
Antonella Trombadore ${ }^{1, *}$, Dusan Rolovic ${ }^{1}$, and Pier Paolo Congiatu ${ }^{2}$ \\ ${ }^{1}$ University of Florence, Florence, Italy \\ 2 Asinara National Park, Asinara, Italy
}

Received: 8 January 2018 / Accepted: 24 February 2018

\begin{abstract}
The paper will present the sustainable and low energy architecture approach that has been developed for a small island in Sardinia, Italy. The island has hosted several prison complexes in the past two centuries, now converted into a National Park, since its creation as a national park its architectural and urban patrimony have been completely abandoned. Its few built-up areas and/or urban developments do have an enormous potential, but past administrations failed in the attempt to offer a commercially attractive model. The project focuses mainly on the development of a Strategic Plan for the regeneration of the island: the main goal is to create completely new activities and functions which are both compatible with its touristic potential and especially with the natural fragility of the ecosystem. These functions have been planned in order to give life and continuous activity to the island, but with extreme care towards its cohesion with the environment and the biodiversity. Results consist in various minor agricultural activities that have been reinstated based on the past activities, and different touristic functions focused on a specific and Eco-responsible market niche. These activities are supported by a complex network of structures and services dedicated to maintaining the balance of the ecosystem intact, while this increases the quality of its offer, thus allowing the creation of a model of sustainable management of natural resources and commercial exploitation without risk for the environment.
\end{abstract}

\section{Territorial challenges}

The Mediterranean islands are characterized by ecosystems and environmental heritage of great value. In a perspective of sustainable development, it becomes necessary to stimulate the regenerative capacity of territories and natural resources, for local identity development in a spirit of cooperation and community involvement. In this process it is necessary to involve actors other than the public administration. Small Medium Interprices (SMEs) play a key role in the implementation and activation of local development. All small islands are characterized by a plurality of decision makers (town, natural park authority, region, state) that are often poorly interconnected. Each of these entities is involved for different and often conflicting reasons in the management of public and collective goods.

In the Mediterranean area you can identify at least three different types of smaller islands, with a long and troubled process of historic settlement and today almost all

\footnotetext{
* e-mail: antonella.trombadore@unifi
}

of these islands are considered protected natural areas, whose management and protection is entrusted to national or regional parks. These include nature reserves such as Montecristo, the former penal colony of Pianosa and Asinara and traditional tourist islands as Giglio, Capraia and Maddalena. Small islands are still full of stories of treasures, memories and symbols that have undergone a process of transformation in recent years, often uncontrolled and characterized by fragmented management, which altered the socio-economic characteristics, the land use and the use and regeneration potential. The Asinara Island, located in the north-west of Sardinia, which includes the National Park of Asinara, has a surface of $51.9 \mathrm{~km}^{2}$ formed by four minor mountain systems that are surrounded and linked by a narrow and flat coastal belt (Fig. 1). The marine island environment is a protected natural area and the island, in its territory, represents an unicum in the Mediterranean area from a geological point of view, as well as its flora and fauna, both on land and sea, given the state of its territorial naturalness and outstanding presence [1]. 


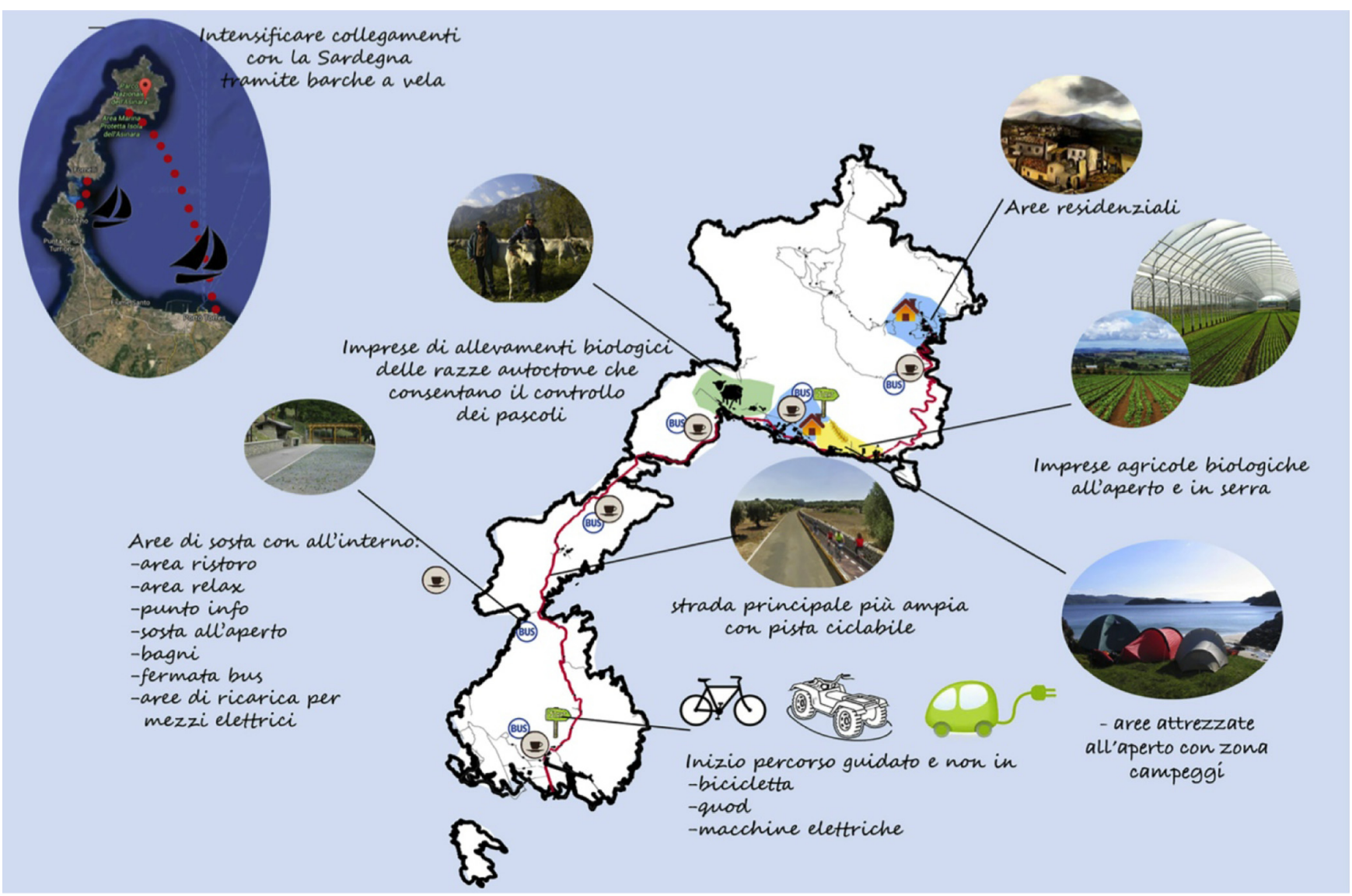

Fig. 1. General view and areas of interest of Asinara Island in Sardinia, Italy.

\subsection{Eco-tourism as opportunity for environmental development of Asinara Island}

In the Mediterranean regions, tourism has always played a strategic role with significant territorial impact in economic and ecological terms, but over the years there has been a strong gap between coastal seaside tourism and cultural and scientific tourism.

This phenomenon, similar in all the islands albeit different in dynamics, resulted in the 70s and 80s exodus and demographic impoverishment of the smaller islands, with consequences on the management and maintenance of housing stock, on the economic activities of the present historic towns and the abandonment of the settlements and the countryside: a depletion of resources, reducing the competences and services that dramatically lowers the tourist attractiveness of the territories, even if placed in prestigious contexts.

The island of Asinara in different centuries underwent alternation of cultural influences, creating a succession of different social dynamics of communities and settlements: from Cala Oliva as the village of Ligurian fishermen to various hospitals in the first and second period, as well as Cala Reale and the agricultural structures of Campu Perdu and Santa Maria, and the prison sectors of Trabuccatu, Fornelli, Tumbarino.
Despite the diversity of the social structure the islanders have allowed us to maintain a dynamic balance between nature and man, being able to manage the entropy of the system in all its complexity, ensuring at the same time the development of agricultural activities as economic and functional aspects of the island and the island life.

The establishment of the Asinara National Park has fortunately slowed down the phenomenon of massive tourism and led to a reversal of the trend, aiming at stimulating a growing demand for high environmental quality services, more aware of the rural and natural resource ecosystems, with a scientific approach and an international feel.

The Asinara territory can be an ideal and real testing ground for the international sharing and the promotion of a sustainable use pattern of low density territories and manmade high concentration of natural and cultural resources. A laboratory in which to test both systems of governance is the creation of ecological networks for smart resource management, integrated with business and $\mathrm{Km0}$ agricultural model (local production of food and beverage).

In this way, it could trigger a virtuous process that brings the revitalization of the area, improving the competitiveness of local SMEs operating levels in the chain of tourist use. Thanks to the experimentation of a governance strategy and a participatory model of innovation and inclusive development, it becomes possible to enhance the system resources as 
well as the economic structure towards a model of ecotourism and responsible tourism, which will produce in the short and medium term an increased green growth in a sustainable development perspective.

\section{The strategic assets: Asinara as archipelago of innovation islands}

It would be interesting to establish a shared process for the drafting of a strategic document on the territorial system of innovation for Asinara, aimed to point out the local guidelines on innovation and technology transfer, identifying opportunities for intervention and the excellence to be valued according to systemic logics of development. Actually, on the Asinara island there are different international scientific activites led by Centre for Environment Education, Crama, as Marine Animal Rescue Centre, the Birds Research Center of Tumbarino, the diving and marine research center (Fig. 2). Besides there is an example of an handcraft excellence represented by Farmasinara, which uses local natural resources (i.e. helichrysum and lavender) to create high-end cosmetics products. In order to improve the network of these activities, it would be important to identify strategies for qualification and upgrading of infrastructure assets of the local system. These strategies could become best practice and pilot projects to foster the territorial innovation, trying to stimulate a more effective regional intervention and programmatic synergies between the various levels of government.

Four emerging priority assets on which to develop six areas of specific actions are:

- scientific and technological research;

- protection of the environmental system;

- green production activities agricultural/rural development; - responsible and experiential tourism.

New activities have been conceived and designed according to the park, which focuses to increase its compatibility with the real needs of the place, and try to offer plausible solutions, from the economic point of view as well as from the feasibility point of view. In particular, the planning was taken into account to organize the activities so as to make available all the valuable aspects of the island, trying to spread them throughout the year, in order to counter the excessive seasonal adjustments tourism.

Six areas of specific actions are:

- models of governance/Management approach;

- network of small green and blue infrastructure (water renewable energy);

- pilot projects - buildings pilot - enhancing building structures;

- human capital training/Coaching;

- communication/Dissemination;

- international networking.

\section{Clusters}

The strategic plan designed to initiate a rebirth and Asinara island regeneration process, through the development of functions compatible with the fragile ecosystem, is based on the introduction of new activities, eco-compatible and integrated with the environment. However, to predict and to best design the arrangement and management of these new activities, it has developed an additional level of planning: blending various activities into Clusters and Networks (Fig. 3).

The term cluster [2] is redefined in this case and applied to the particular natural and cultural context in which we find ourselves. It is to divide the island into several parts, which are considered self-sufficient but closely connected and collaborating. This brings us to the concept of the island in the island: a complex of buildings, structures, agricultural and natural areas full of all types of services and activities related to its function. This self-sufficiency is related to one (or more) particular activity, well defined, with a series of facilities dedicated to it. These structures are usually obtained from the pre-existing buildings. Each cluster has a main theme, and in some cases we have an additional division, as some activities are located in various parts of the island.

\section{Asinara green in_farm_structure: a pilot project}

The project concentrated mainly towards creating a wide Strategic Plan for the island regeneration: its main goal was creating completely new activities and functions that are compatible both with its touristic potential and especially with its natural fragility. These functions have been planned in order to give life and continuous activity to the island, but with extreme attention towards its cohesion with nature and biodiversity. Results consist in various agricultural activities that have been reinstated based on the past activity, and different touristic functions that should appeal to a specific and eco-responsible target of clients. These various activities have been supported by a complex network of structure and services, dedicated to maintaining the island's ecosystem intact, and improving its offer and abilities to create both natural and commercial environment (Fig. 4).

The Strategic Plan has been developed with various strategies for reaching a sustainable and self-sufficient island, and has included various technological solutions. For example, there is an extensive use of building integrated Photovoltaic System (PV) and wind turbines which are inserted in architectural and urban environments in a non-invasive way. Other strategies include a broad water-harvesting network that includes harvesting rain water from roofing, in urban areas, and especially in agricultural areas, given its high need and waste of water used for irrigation. Other strategies include a revised mobility plan that points towards complete elimination of $\mathrm{CO}_{2}$ emissions, giving priority to use of electric cars, as well as encouraging cycling and walking, given various beautiful ndatural areas on the island. A waste management plan has been developed as well, with inclination towards biogas production as well as anaerobic digestion that could turn organic waste into heat, electricity and compost for agricultural activities (Fig. 5). 

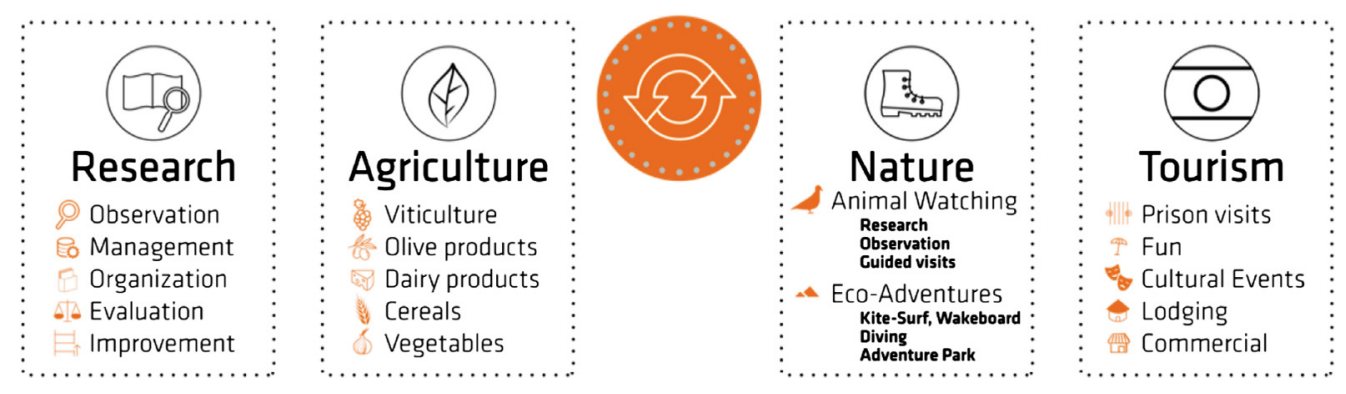

Fig. 2. General view of the assets.

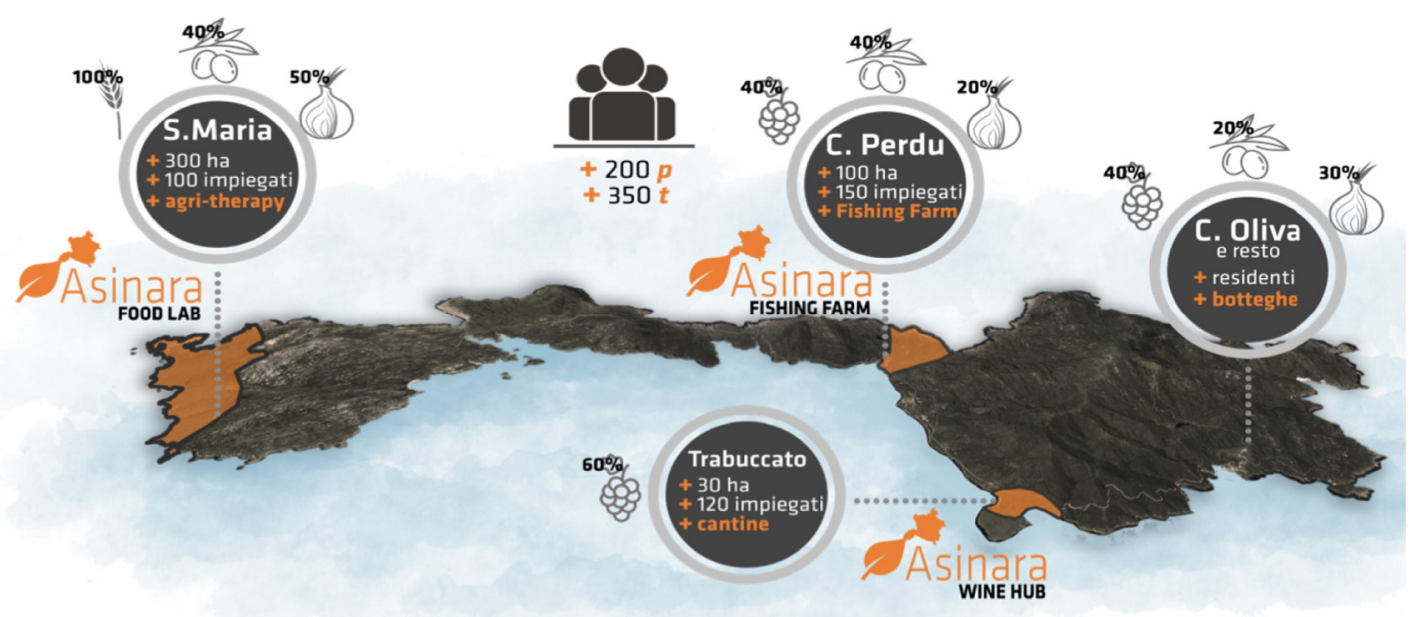

Fig. 3. The location and activities of the Cluster in the Master Plan.

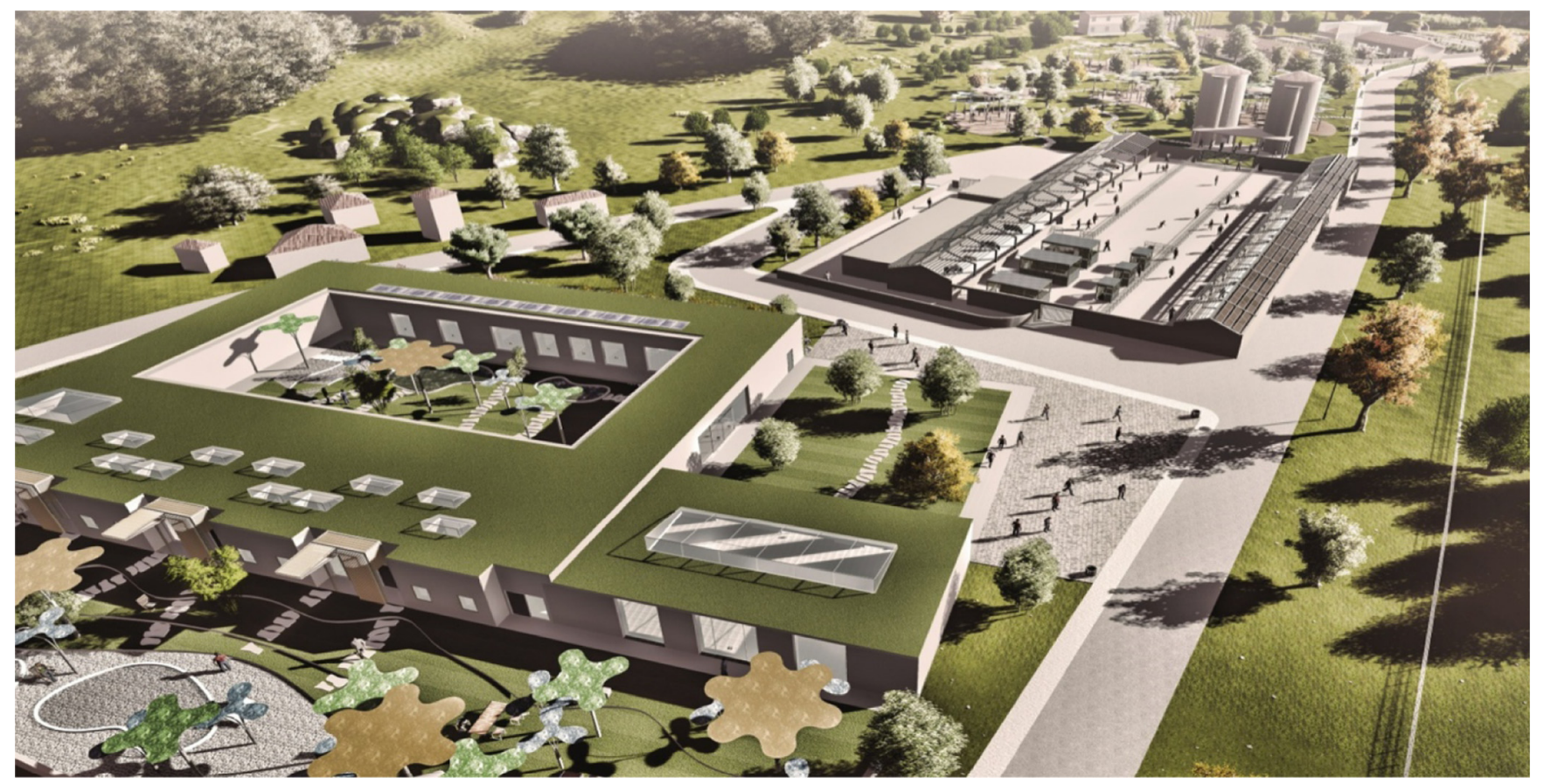

Fig. 4. General view of the Pilot Project. 


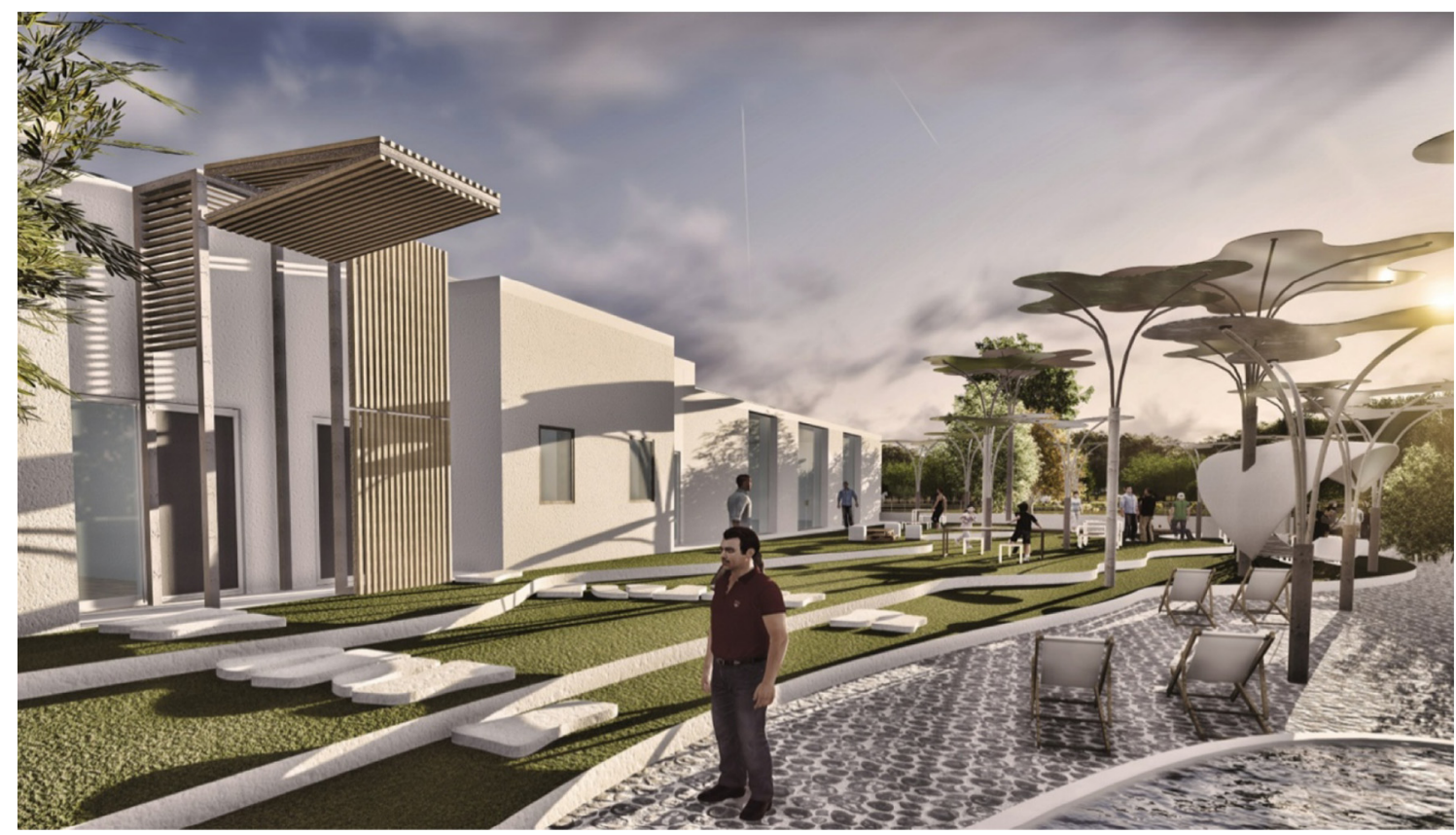

Fig. 5. General concept of the Pilot Project.

The final and main level of the project was the revitalization of the former prison sector Santa Maria as an international laboratory for ecotourism. This complex, located in the south of the area, has been used in the past as a farm for a particular group of inmates, and is situated near a field of nearly 200 ha that can be turned into an agricultural farm complex. The concept behind the project was about creating a structure that is both productive and commercial, that offers a unique and naturalistic way of approaching and learning processes of agriculture, but that also offers beautiful and relaxing luxuries such as a slow food restaurant, exclusive green suites, a kitchen laboratory and an agri-therapy for children. It has been conceived as multifunctional set of buildings with green public spaces inbetween, perfectly connected and able to offer a full set of activities and leisure for tourists as well as researchers. It concentrates primarily on 3 buildings.

The building is a prison structure that has been revitalized and refreshed to house a slow-food restaurant and various suites for visitors. The project leaves internal disposition practically intact, but intervenes on buildings facades, making it much more open and illuminated, creating almost semi-open spaces that collaborate perfectly with the green surrounding them (Fig. 6). These facades have been elaborated with some air and light-treating technologies, in order to reach a full-scale comfort inside the suites and restaurants. These technologies include:

- EvaCool, a separated façade system built with tube structure that envelopes plants and hygroscopic materials that help cool air via evaporation, and channel it inside the building with specially designed cross-ventilation systems; - a special in-suite greenhouse that uses a skylight for water harvesting and for better illumination, increasing the climatic comfort in the suite as well as indirect and diffused illumination;
- inside and outside gardens that house a terrace-based water harvesting system;

- CanoPV+, a modular, tree-like canopy structure, with integrated photovoltaic cells that serves both as energy efficient element as well as for creating shaded spaces in outside gardens.

\section{Environmental and economic impact: final considerations}

The plan is integrated with other strategies for sustainability, an essential part of planning for a fragile environment as the island of Asinara. It is important to reaffirm the peculiarity of the environment and the natural balance of the plan. The inclusion of new features, therefore, must not only be compatible from an ecological point of view, economic and social, but must be accompanied by a relevant resource management in an intelligent and forward-looking way. As for the identification of intervention strategies, the method adopted was to create a schedule of references, later adapted and redesigned to be part of the strategic plan. These solutions are based on a number of different possible interventions, ranging from energy efficiency field to the intelligent management of the waste and the organization of mobility.

\subsection{Water}

Water is one of the most critical resources within the island, because the whole system is based on the management of a network of reservoirs that provide water for all uses on the island. The new strategies will be combined with the existing rainwater management system. It is expected, in the first place, a total recovery and restoration of tanks, with particular attention to those relevant to urban areas, as provided by the Park Plan. 

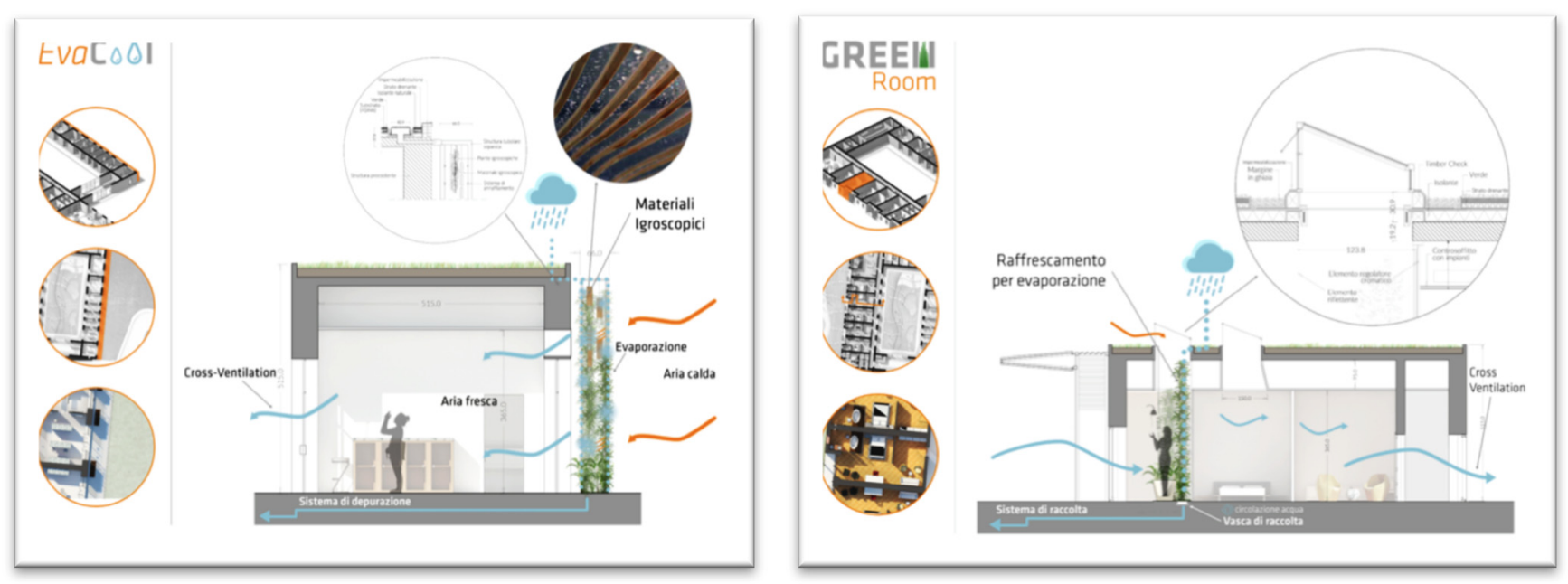

Fig. 6. General passive cooling strategies.

\subsection{Energy}

The second resource planning is the subject of sustainable energy. Compared to the management of water, the electricity system is in much better condition.

Electricity is supplied to the island by an underwater cable, which is approximately $4 \mathrm{~km}$ long. It continues along the main road, extending along the entire island. It is in a satisfactory condition, and the plan provides a repair and recovery infrastructure in order to obtain siutable energy production to absorb the new features and their needs. The strategic plan foresees the inclusion of some structures and solutions for additional energy savings and renewal of resources. In particular the use of photovoltaic materials, will be implemented as BIPV (building integrated photovoltaic) with a high aesthetical value, in order to avoid a strong visual impact.

\subsection{Waste management}

The collection, waste management and disposal are a very interesting topic within the strategic plan. Although the Plan of the Park identifies the current system as functional and satisfying, the inclusion of new features and new structures creates an increase in tourist flows that could pose serious problems for the collection and management of waste. The plan provides primarily a strengthening and expansion of facilities suitable for the collection of waste and testing of an Anaerobic Digestion system [3].

\subsection{Mobility}

It is also planned to incorporate a vision and a completely new strategy regarding the island. Given the particularly sensitive environment, the plan provides for a maximum
$\mathrm{CO}_{2}$ emission control, eliminating the private cars, except for cases emergency or support services. It thus opens the possibility to also create a small network of public transport, of small size and $100 \%$ electric [4].

Furthermore, it is expected that the replacement will be done using electrical machines, complemented by different shelters and small facilities for information of all types. It also intends to strengthen the use of bicycles and enhance the movement on foot, a concept that is also part of the project and the natural/sports activities related to different contexts.

\subsection{The economic impact of the pilot project}

Based on an integrated and participatory management of all new activities, as well as on the inclusion of public and private institutions of various levels, the park plan also is part of a network of European funded projects and supported by the Sardinia Region. The strategic plan is part of this context and the intervention strategies are fully integrated into European design rules and sustainable approaches. The economic concept includes a number of initial investments by the Sardinian region, local and national authorities and various cooperatives with an interest in the activities proposed by the plan. In addition it is expected that the plan could fall within the framework of the Europea Union (EU) funding. This initial funding would provide a base for the first series of interventions, in particular the organization, pre-design and placement of some new functions for the park. These early interventions would be directed mainly to the activation of agricultural production, rehabilitation of the relevant structures and the creation of a suitable environment for the development of niche tourism. Realization of these assets and related facilities would allow the launching of agricultural production as well as completion of the tourist island (Fig. 7). 


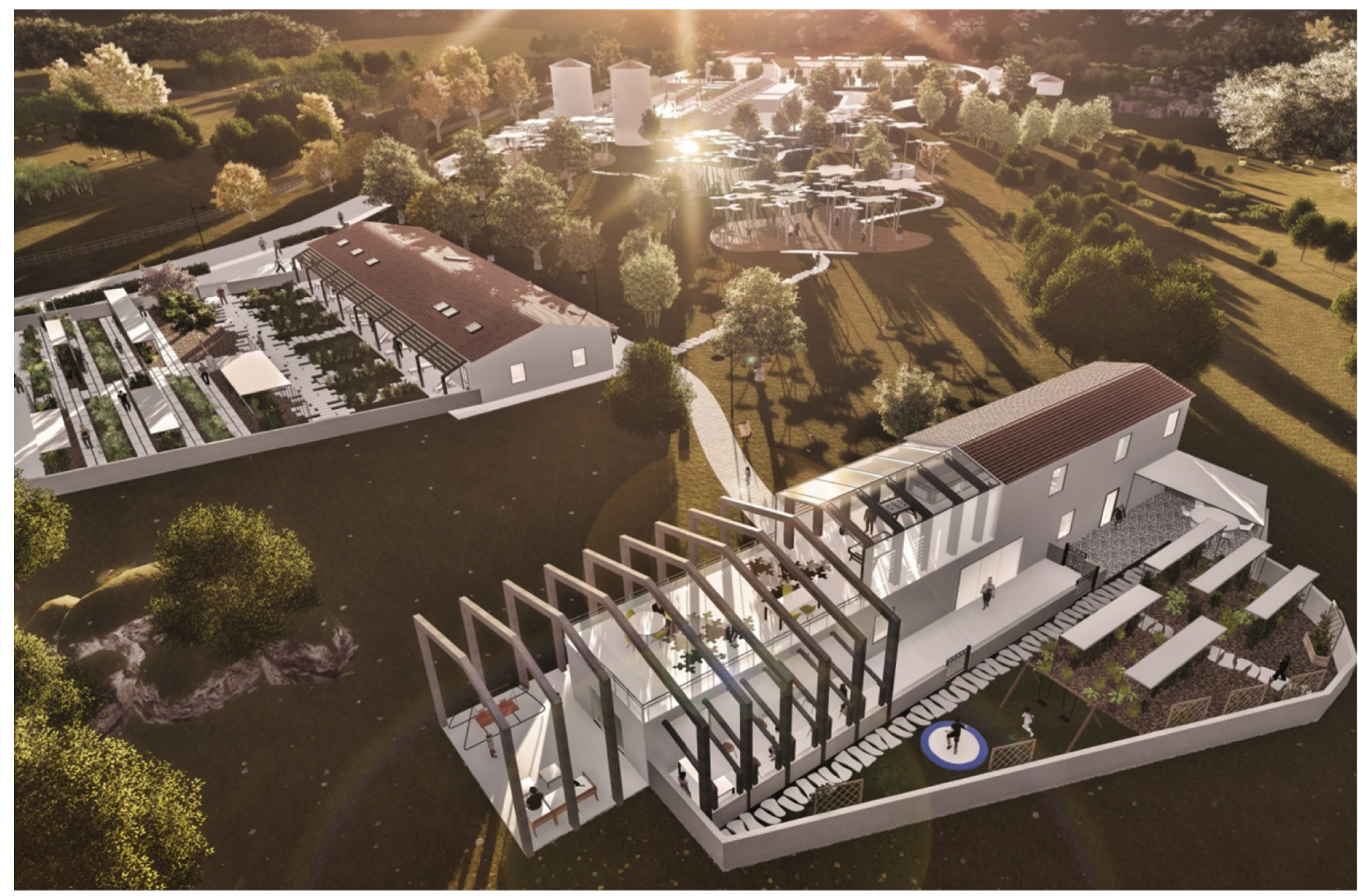

Fig. 7. General view of the Pilot Project.

These activities, in turn, could provide further economic basis for the subsequent development and implementation of the rest of the structures and functions, in particular the stabilization of the local brand and the creation of necessary conditions for saving resources [5]. This plan provides for the achievement of a high level of self-sufficiency in different scales, with the idea that the new activities and modern structures could possibly become a basis for economic, cultural and social development of the Asinara island.

\section{References}

1. PARCO NAZIONALE DELL'ASINARA, Piano del Parco, Relazione Genarale, resp. Vanni Maciocco, [on line] available on web site http://www.parcoasinara.org

2. MANUALE ALCOTRA, La creazione di Living Lab transfrontalieri .Torino Luglio 2013 [on line] Available on web site http://www.alcotra-innovazione.eu

3. AD NETT, The European Anaerobic Digestion Network [on line] available on web site http://www.adnett.org

4. ARUP, Cities Alive - Rethinking Green Infrastructures, Foresight (2014)

5. TROMBADORE Antonella. Mediterranean Smart Cities, Edizioni Altralinea, Firenze (2015)

Cite this article as: Antonella Trombadore, Dusan Rolovic, Pier Paolo Congiatu, Green infrastructure and low energy architecture for eco-tourism in Asinara island, Renew. Energy Environ. Sustain. 3, 2 (2018) 